\title{
ANTIBACTERIAL ACTIVITY AGAINST BACILLUS SUBTILIS AND ANTIOXIDANT PROPERTIES OF METHANOL EXTRACTS FROM GARCINIA LATISSIMA MIQ. LEAVES
}

\author{
NENENG SITI SILFI AMBARWATI ${ }^{1,2}$, BERNA ELYA ${ }^{2 *}$, AMARILA MALIK ${ }^{2}$, MUHAMMAD HANAFI ${ }^{3,4}$, HANITA OMAR $^{5}$ \\ ${ }^{1}$ Department of Cosmetology, Faculty of Engineering, Universitas Negeri Jakarta, Jakarta 13220, Indonesia. ${ }^{2}$ Department of \\ Pharmaceutical Biology, Faculty of Pharmacy, Universitas Indonesia, Depok 16424, Indonesia. ${ }^{3}$ Research Centre for Chemistry, Indonesian \\ Institute of Sciences (LIPI), Tangerang 15314, Indonesia. ${ }^{4}$ Department of Pharmaceutical Chemistry, Faculty of Pharmacy, Universitas \\ Pancasila, Jakarta 12640, Indonesia. ${ }^{5}$ Chemistry Division, Centre for Foundation Studies in Science, University of Malaya, Kuala Lumpur \\ 50603, Malaysia. Email: berna.elya@gmail.com \\ Received: 20 June 2018, Revised and Accepted: 25 August 2018
}

\section{ABSTRACT}

Objective: The objective of this study was to identify fractions with the highest antibacterial activity against Bacillus subtilis and to determine antioxidant activities and establish the chromatographic fractions as candidate antibacterial and antioxidant agents.

Methods: Extracts were fractionated using column chromatography, and antibacterial activities were assayed by the analyses of inhibition zones and bioautography, as well as by broth microdilution techniques. Antioxidant activities were evaluated using the 2,2-diphenyl-1-picrylhydrazyl (DPPH) assay.

Results: The strongest antibacterial activity against B. subtilis (ATCC 6633) was observed with fractions B and C obtained in this research, with a minimum inhibitory concentration value of $312.5 \mu \mathrm{g} / \mathrm{mL}$. The effective percentage (EP) value of crude extract at $10 \mu \mathrm{g} / \mathrm{mL}$ was $29.47 \pm 2.01 \%$. Fractions C and D had greater EP values than the crude extract, whereas fraction D had the highest scavenging activity against DPPH free radicals $(37.73 \pm 1.44 \%)$ when used at $10 \mu \mathrm{g} / \mathrm{mL}$. The half effective concentration of the extract was $23.40 \mu \mathrm{g} / \mathrm{mL}$, whereas that of the most active fraction D was $19.38 \mu \mathrm{g} / \mathrm{mL}$ and quercetin as positive control was $3.72 \mu \mathrm{g} / \mathrm{mL}$.

Conclusion: The present data confirm that fractions of methanol extract from Garcinia latissima Miq. leaves possess antibacterial and antioxidant activities. These observations may facilitate the development of antimicrobial phytomedicines with a wide spectrum of activities and standardized antioxidant properties.

Keywords: 2,2-diphenyl-1-picrylhydrazyl, Bacillus subtilis, Fractions, Garcinia latissima Miq., Minimum inhibitory concentration.

(c) 2018 The Authors. Published by Innovare Academic Sciences Pvt Ltd. This is an open access article under the CC BY license (http://creativecommons. org/licenses/by/4. 0/) DOI: http://dx.doi.org/10.22159/ijap.2018.v10s1.06

\section{INTRODUCTION}

The frequency of life-threatening diseases due to pathogenic microorganisms has risen globally, and it is becoming one of the leading causes of morbidity and mortality in immunocompromised patients [1]. The control of antimicrobial resistance requires the use of better and more effective antibiotics [2], and appropriate antimicrobials with no side effects are urgently needed [1]. As estimated by the World Health Organization (WHO), about 75\% of the population in developing countries relies on plant-based traditional medicines [3]. Plants, such as vegetables and medicinal herbs, contain numerous molecules with free radical scavenging and antioxidant properties, such as nitrogen compounds, phenolic compounds, terpenoids, vitamins, and various endogenous metabolites [1]. Many studies have identified new antimicrobial and antioxidant compounds from natural sources, including animals, microorganisms, and plants. However, because botanical flora includes thousands of organisms, numerous medicinal compounds remain unexploited [1].

Previous studies show that fractions of methanol extract from Garcinia latissima Miq. leaves are active against Bacillus subtilis. At a concentration of $2 \%$, inhibition zones with diameters of $9.9 \pm 0.786 \mathrm{~mm}$ were obtained with these extracts against $B$. subtilis. These extracts also had minimum inhibition concentration (MIC) values of $10,000 \mu \mathrm{g} / \mathrm{mL}$ and minimum bactericidal concentration values of $20,000 \mu \mathrm{g} / \mathrm{m}$ [4] As indicated in previous phytochemical screening studies, methanol extracts of G. latissima Miq. contain saponin and tannin [4]. In this study, this extract was fractioned using column chromatography with silica gel stationary phase and mobile phases of increasing polarity. Antibacterial activities of the resulting fractions were tested against B. subtilis, and antioxidant properties of extracts and fractions were compared. The objective of this study was to identify fractions with the highest antibacterial activity against $B$. Subtilis and to determine antioxidant activities and establish the chromatographic fractions as candidate antibacterial and antioxidant agents.

\section{METHODS}

Microorganisms

Antibacterial activities of test substances were determined against B. subtilis (ATCC 6633) cells, maintained on an agar slant in a refrigerator at $4^{\circ} \mathrm{C}$.

Phytochemical materials

Test materials were obtained during our previous study and included methanol extracts (Fig. 1) of leaves from plants available at the center for plant conservation at Bogor Botanical Garden. In our previous research, we further fractionated methanol extract and an obtained fraction was then named: Fraction $\mathrm{B}$, fraction $\mathrm{C}$, fraction $\mathrm{D}$, fraction $\mathrm{E}$, fraction $\mathrm{F}$, and fraction $\mathrm{G}$ which bioautography of active fractions were presented in Fig. 1.

Fraction B was eluted with $n$-hexane:ethyl acetate (1:1), fractions $C$ and D were eluted with $n$-hexane:ethyl acetate (1:3), fraction $E$ was eluted with n-hexane:ethyl acetate (1:9), fraction $\mathrm{F}$ was eluted with ethyl acetate:dichloromethane $(4: 1)$, and fraction $G$ was eluted with ethyl acetate:dichloromethane $(4: 1)$. 


\section{Fractionation}

The methanol extract (25.41 g) was fractionated using a chromatographic column filled with Silica Gel G60 with a diameter of $45 \mathrm{~mm}$ and a height of 330 mm using a 70-230 mesh (E Merck 7734.1000) stationary phase. The mobile phase was a gradient of solvents with increasing polarity (n-hexane, ethyl acetate, and methanol). The flow rate was $20 \mathrm{~mL} / \mathrm{min}$, and 100-mL elutes were collected in bottles [5]. The contents of these bottles were assayed using thin-layer chromatography (TLC). The fraction with identical chromatographic patterns was collected, and solvents were evaporated under a flow of air until dry and stored in a refrigerator

\section{In vitro antibacterial assays}

\section{Preparation and standardization of inocula}

Bacterial cell suspensions were prepared separately from 24-h Mueller-Hinton agar cultures. Colonies of microorganisms were diluted in $0.9 \% \mathrm{NaCl}$ to obtain a McFarland standard turbidity of 0.5 using visual assessments and then diluted to approximately $10^{6} \mathrm{CFU} / \mathrm{ml}[1]$.

\section{Broth microdilution test}

To determine MIC values of test substances, broth microdilution assays were performed in 96-well microplates [1]. Assays in 96-well microplates were prepared by adding $50-\mu \mathrm{L}$ aliquots of test substances to the first wells and three-fold serial dilutions in subsequent wells. Standardized inocula were then added to each well in $50-\mu \mathrm{L}$ aliquots, leading to a bacterial concentration of approximately $10^{6} \mathrm{CFU} / \mathrm{mL}$ in a total volume of $100 \mu \mathrm{L}$. Serial dilutions produced final concentrations of $20,000,10,000,5000,2500,1250,625$, and $312.5 \mu \mathrm{g} / \mathrm{mL}$. The antibiotic gentamicin was used as a positive control as well as dimethyl sulfoxide. Inoculated broths were used in all experiments [6]. The contents of wells were mixed thoroughly, and the microplates were then covered and incubated at $37^{\circ} \mathrm{C}$ for $24 \mathrm{~h}$ [7]. Bacterial growth was monitored colorimetrically using thiazolyl blue tetrazolium bromide (3-(4,5-Dimethylthiazol-2-Yl)-2,5-diphenyltetrazolium bromide [MTT], BII Life Sciences) assays [8]. MICs were defined as the lowest concentration of test substances that prevented visible growth of microorganisms [9].

\section{Antioxidant activities using 2,2-diphenyl-1-picrylhydrazyl (DPPH)} assays

Radical scavenging activities of extracts and compounds were determined using the stable free radical, DPPH [1]. Test substances from fractions were added at $100 \mu \mathrm{g} / \mathrm{mL}$ and dissolved with DPPH $(150 \mathrm{mM})$ in methanol $[10,11]$. DPPH radical solution was prepared, and $180-\mu \mathrm{L}$ aliquots were mixed with $20-\mu \mathrm{L}$ aliquots of the test sample or reference substance in 96-well microplates [12]. After mixing, plates were incubated at room temperature in the dark for $30 \mathrm{~min}$ [13]. Absorbance was then recorded at $516 \mathrm{~nm}$ using a Versamax ELISA Microplate Reader (USA) [14]. All tests were conducted in triplicate. Percentage reductions in DPPH radical activity in the presence of test samples were calculated using the following formula [15].

Effectivity percentage $(\mathrm{EP})=([$ Absorbance of DPPH - Absorbance of mixture]/Absorbance of $\mathrm{DPPH}) \times 100$, where the mixture contained extract or fraction and DPPH dissolved in methanol.

The half effective concentration $\left(\mathrm{EC}_{50}\right)$ values were calculated as the concentration of sample required to scavenge $50 \%$ of DPPH free radicals and were determined using plots of percentage inhibition versus sample concentration in triplicates [16]. These values were used to identify the most active fractions and extracts.

\section{RESULTS}

\section{Fractionation}

A total of 14 fractions were eluted from TLC, and these were labeled A, B, C, D, E, F, G, H, I, J, K, L, M, and N. Fractionation results from methanol extracts of G. latissima Miq. leaves are presented in Table 1.
Antibacterial properties of chromatographic fractions

The results of inhibition zone assays with $20,000 \mu \mathrm{g} / \mathrm{mL}$ fractions from G. latissima leaf extracts are shown in Table 2.

In the inhibition zone assays, fraction $\mathrm{C}$ showed the highest antibacterial activity, with an inhibition zone of $8.967 \pm 0.208 \mathrm{~mm}$ in diameter. Fractions $\mathrm{A}, \mathrm{H}, \mathrm{I}, \mathrm{J}, \mathrm{K}, \mathrm{L}, \mathrm{M}$, and $\mathrm{N}$ did not produce significant inhibition zones against $B$. subtilis cultures.

Fractions B and C (MIC, $312.5 \mu \mathrm{g} / \mathrm{mL}$ ) showed the highest antibacterial activities against B. subtilis (Table 3).

\section{Antioxidant activity tests}

Antioxidant activity assays were performed using the DPPH scavenging method with a microplate reader (Versamax ELISA Microplate Reader, USA) at wavelength maxima for DPPH of $516 \mathrm{~nm}$. Quercetin was used as a control and showed an $\mathrm{IC}_{50}$ of $3.72 \mu \mathrm{g} / \mathrm{mL}$. Preliminary antioxidant assays of extracts were performed using crude extract and fractions $\mathrm{A}$, B, C, D, E, F, G, H, I, J, K, L, M, and N at $10 \mu \mathrm{g} / \mathrm{mL}$.

In these experiments, fraction D showed the highest antioxidant activity, as indicated by effectivity percentage (EP) values (Table 4). EP values were $37.73 \pm 1.44 \%$ and $29.47 \pm 2.01 \%$ for fraction D and the crude methanol extract, respectively (Table 4). The $\mathrm{EC}_{50}$ value of fraction $\mathrm{D}$ was $19.38 \mu \mathrm{g} / \mathrm{mL}$, whereas that of the crude extract was $23.40 \mu \mathrm{g} / \mathrm{mL}$ (Table 5) and that of quercetin was $3.72 \mu \mathrm{g} / \mathrm{mL}$ (Table 5).

Table 1: Fractionation of methanol extracts from $G$. latissima Miq. leaves

\begin{tabular}{llll}
\hline Fraction & $\begin{array}{l}\text { Bottle } \\
\text { number }\end{array}$ & $\begin{array}{l}\text { Fraction } \\
\text { weight } \mathbf{( g )}\end{array}$ & $\begin{array}{l}\text { Fraction } \\
\text { percentage (\%) }\end{array}$ \\
\hline $\mathrm{A}$ & $1-5$ & 0.5402 & 3.30 \\
$\mathrm{~B}$ & $43-70$ & 0.2576 & 1.58 \\
$\mathrm{C}$ & $71-77$ & 0.2520 & 1.54 \\
$\mathrm{D}$ & $78-84$ & 1.4587 & 8.92 \\
$\mathrm{E}$ & $85-112$ & 0.3767 & 2.30 \\
$\mathrm{~F}$ & $113-118$ & 1.7375 & 10.62 \\
$\mathrm{G}$ & $119-142$ & 1.9141 & 11.70 \\
$\mathrm{H}$ & $143-148$ & 1.691 & 10.34 \\
$\mathrm{I}$ & $131-137$ & 1.673 & 10.23 \\
$\mathrm{~J}$ & $138-147$ & 1.4374 & 8.79 \\
K & $148-150$ & 0.9471 & 5.79 \\
L & $151-158$ & 1.1978 & 7.32 \\
M & $159-188$ & 2.1875 & 13.37 \\
N & $189-195$ & 0.6893 & 4.21 \\
Total weight of fraction & 16.3599 & \\
\hline
\end{tabular}

G. latissima: Garcinia latissima

Table 2: Inhibition zone assays with $20,000 \mu \mathrm{g} / \mathrm{mL}$ fractions from G. latissima Miq. leaf extracts

\begin{tabular}{ll}
\hline Fraction & $\begin{array}{l}\text { Diameters of inhibition zones (mm) } \\
\text { against Bacillus subtilis }\end{array}$ \\
\hline A & 0 \\
B & $7.467 \pm 0.153$ \\
C & $8.967 \pm 0.208$ \\
D & $8.133 \pm 0.569$ \\
E & $7.367 \pm 0.569$ \\
F & $7.800 \pm 0.100$ \\
G & $7.100 \pm 0.361$ \\
H & 0 \\
I & 0 \\
J & 0 \\
K & 0 \\
L & 0 \\
M & 0 \\
N & 0 \\
Gentamicin & $29.175 \pm 0.983$ \\
\hline
\end{tabular}

G. latissima: Garcinia latissima 


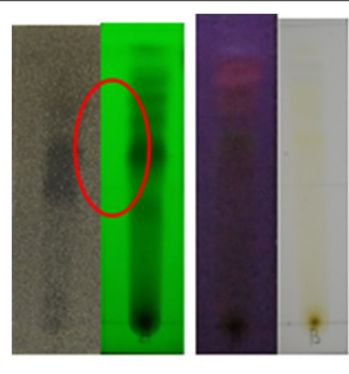

Fraction B

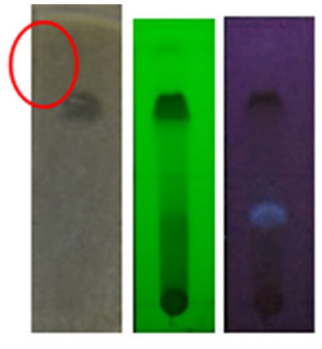

Fraction E
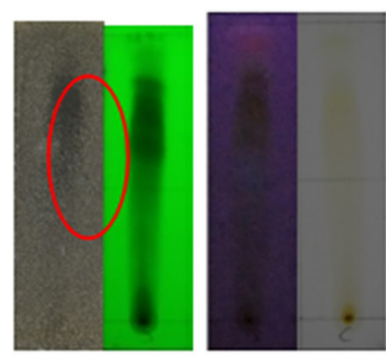

Fraction C
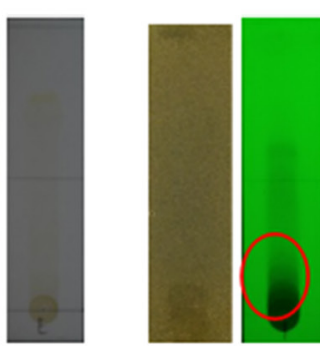

Fraction $\mathrm{F}$

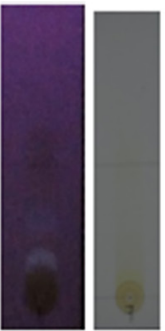

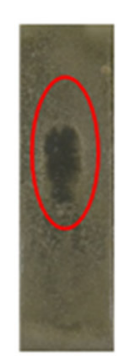

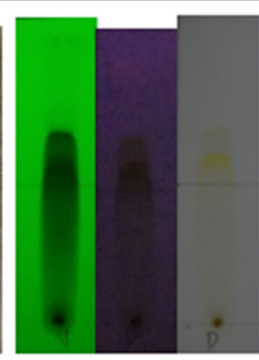

Fraction D
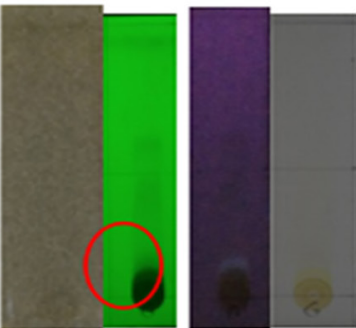

Fraction G

Fig. 1: Bioautography of active fractions from methanol extracts of Garcinia latissima Miq. leaves against Bacillus subtilis bacteria

Table 3: MIC of fractions of methanol extracts from G. latissima Miq. leaves against $B$. subtilis

\begin{tabular}{ll}
\hline Fraction & MIC $(\boldsymbol{\mu g} / \mathbf{m L})$ \\
\hline A & 1250 \\
B & 312.5 \\
C & 312.5 \\
D & 625 \\
E & 625 \\
F & 1250 \\
G & 1250 \\
H & 2500 \\
I & 5000 \\
J & 2500 \\
K & 5000 \\
L & 5000 \\
M & 5000 \\
N & 5000 \\
Gentamicin & 25 \\
DMSO & $>5000$ \\
\hline
\end{tabular}

B. subtilis: Bacillus subtilis, G. latissima: Garcinia latissima, DMSO: Dimethyl sulfoxide

Table 4: EP values of crude extract and the ensuing fractions of G. latissima Miq. leaves at $10 \mu \mathrm{g} / \mathrm{mL}$

\begin{tabular}{ll}
\hline Sample & EP (\%) \\
\hline Extract & $29.47 \pm 2.01$ \\
Fraction A & $20.68 \pm 3.29$ \\
Fraction B & $7.93 \pm 2.97$ \\
Fraction C & $29.66 \pm 0.80$ \\
Fraction D & $37.73 \pm 1.44$ \\
Fraction E & $23.83 \pm 1.83$ \\
Fraction F & $18.91 \pm 2.85$ \\
Fraction G & $17.96 \pm 1.96$ \\
Fraction H & $16.76 \pm 1.27$ \\
Fraction I & $9.60 \pm 1.45$ \\
Fraction J & $9.79 \pm 2.52$ \\
Fraction K & $7.83 \pm 1.89$ \\
Fraction L & $15.23 \pm 0.95$ \\
Fraction M & $13.51 \pm 0.91$ \\
Fraction N & $18.82 \pm 4.25$ \\
\hline
\end{tabular}

EP: Effectivity percentage, G. latissima: Garcinia latissima
Table 5: Antioxidant activities of crude extract and fraction $D$ of methanol extracts from G. latissima Miq. leaves $\left(\mathrm{EC}_{50}, \mu \mathrm{g} / \mathrm{mL}\right)$

\begin{tabular}{ll}
\hline Sample & $\mathbf{E C}_{\mathbf{5 0}}(\boldsymbol{\mu g} / \mathbf{m L})$ \\
\hline Fraction D & 19.38 \\
Extract & 23.40 \\
Quercetin & 3.72 \\
\hline
\end{tabular}

G. latissima: Garcinia latissima, $\mathrm{EC}_{50}$ : Half effective concentration

\section{DISCUSSION}

\section{In vitro antibacterial activities}

Crude methanol extract from G. latissima leaves and its fractions produced antibacterial activity against $B$. subtilis. The present fractionation process separated extracts into 14 fractions (A-N) with fewer active ingredients than the parent extract, and fractions $B$ and $\mathrm{C}$ had greater activity when compared with the other fractions. In the most active fractions, the fractionation process likely reduced the antagonistic effects of contaminating compounds [1].

The relationship between antibacterial activity and contents of active compounds in plant extracts or fractions of G. latissima have been investigated in multiple previous studies [1,17-21]. Moreover, phytochemical tests of methanol extracts of G. latissima leaves showed the presence of tannin and saponin, which are known phytochemicals with health benefits and biological activities [4]. The MIC of the most active fraction of methanol extracts from G. latissima leaves against B. subtilis was $312.5 \mu \mathrm{g} / \mathrm{mL}$. In contrast, the MIC of the crude methanol extract was $10,000 \mu \mathrm{g} / \mathrm{mL}$ [4], indicating a dramatic improvement in the activity.

The present assays of antibacterial activity showed that the chromatographic fractions of methanol G. latissima leaf extracts contain compounds that inhibit the growth of $B$. subtilis, with significant increases in areas of inhibition [22]. We also used contact bioautography to qualitatively analyze antibacterial activities [23], and observed zones of bacterial growth inhibition around spots of fractions B, C, D, E, F, and G, indicating the presence of useful agents in these fractions [24]. Moreover, differing localizations of clear zones between fractions indicated that each fraction contained different active compounds [25]. 
Antioxidant activities of crude extract and its fractions

Reductions of DPPH radical were estimated in terms of EP and for the crude methanol extract of $G$. latissima Miq. leaves, the EP was $29.47 \pm 2.01 \%$. Fractions C and D had higher EPs of $29.66 \pm 0.80 \%$ and $37.73 \pm 1.44 \%$, respectively.

Antioxidant activities of natural materials have been widely studied and reviewed [1]. In the present study, we showed that the crude extract had free radical scavenging activity, but the most active fraction $\mathrm{D}$ had a lower $\mathrm{EC}_{50}$ value. Fraction D had a stronger antioxidant activity than crude extract; the antioxidant activity of quercetin was much greater $\left(\mathrm{EC}_{50}=3.72 \mu \mathrm{g} / \mathrm{mL}\right)$.

The effects of quercetin are reportedly influenced by the degree to which it can prevent oxidation of other molecules, which also neutralize free radicals both actively and passively [1]. As reported in previous studies, G. latissima extract contains saponins and tannins, and these active compounds likely contribute to the antioxidant activities $[1,4]$

\section{CONCLUSION}

We confirm that $G$. latissima Miq. leaves have antibacterial and antioxidant properties. Our data contribute to the standardization of antimicrobial phytomedicines with a wide spectrum of activities from G. latissima Miq. leaf extract fractions.

\section{ACKNOWLEDGMENT}

We acknowledge the financial support of the Doctoral Final Assignment Grant from University of Indonesia 2018

\section{CONFLICTS OF INTEREST}

The authors declare that they have no conflicts of interest

\section{REFERENCES}

1. Njateng GS, Du Z, Gatsing D, Mouokeu RS, Liu Y, Zang HX, et al. Antibacterial and antioxidant properties of crude extract, fractions and compounds from the stem bark of polyscias fulva hiern (Araliaceae). BMC Complement Altern Med 2017;17:99.

2. Kaneria M, Baravalia Y, Vaghasiya Y, Chanda S. Determination of antibacterial and antioxidant potential of some medicinal plants from Saurashtra Region, India. Indian J Pharm Sci 2009;71:406-12.

3. World Health Organization. Traditional Medicine-Growing Needs and Potential. Vol. 2. Canada: World Health Organization Policy Perspectives on Medicines; 2002. p. 1-6.

4. Ambarwati NS, Ahmad I, Elya B, Malik A, Hanafi M. Pharmacognostic and antimicrobial studies of Garcinia latissima Miq. Leaves (Clusiaceae). Pharmacogn J 2017;9:73-8

5. ZahradNíkOVá L, Schmidt S, SékeLyOVá Z, Sekretár S. Fractionation and identification of some phenolics extracted from evening primrose seed meal. Czech J Food Sci 2008;26:58-64.

6. Dickson RA, Houghton PJ, Hylands PJ. Antibacterial and antioxidant cassane diterpenoids from Caesalpinia benthamiana. Phytochemistry 2007;68:1436-41.

7. Kuete V, Ngameni B, Simo CC, Tankeu RK, Ngadjui BT, Meyer JJ, et al. Antimicrobial activity of the crude extracts and compounds from ficus chlamydocarpa and Ficus cordata (Moraceae). J Ethnopharmacol 2008; 120:17-24

8. Abate G, Mshana RN, Miörner H. Evaluation of a colorimetric assay based on 3-(4,5-dimethylthiazol-2-yl)-2,5-diphenyl tetrazolium bromide (MTT) for rapid detection of rifampicin resistance in mycobacterium tuberculosis. Int J Tuberc Lung Dis 1998;2:1011-6.

9. Wiegand I, Hilpert K, Hancock RE. Agar and broth dilution methods to determine the minimal inhibitory concentration (MIC) of antimicrobial substances. Nat Protoc 2008;3:163-75.

10. Nuutila AM, Puupponen-pimia R, Aarni M. Comparison of antioxidant activities of onion and garlic extracts by inhibition of lipid peroxidation and radical scavenging activity. Food Chem 2003;81:485-93.

11. Shyamala BN, Gupta S, Lakshmi AJ, Prakash J. Leafy vegetable extracts-antioxidant activity and effect on storage stability of heated oils. Innov Food Sci Emerg Technol 2005;6:239-45

12. Ojeda-Sana AM, van Baren CM, Elechosa MA, Juárez MA, Moreno S. New insights into antibacterial and antioxidant activities of rosemary essential oils and their main components. Food Control 2013;31:189-95.

13. Endo Y. Antioxidant effects of chlorophyll and pheophytin on the autoxidation of oils in the dark. II. The mechanism of antioxidative action of chlorophyll. J Am Oil Chem Soc 1985;62:1387-90.

14. Heo SJ, Lee GW, Song CB, Jeon YJ. Antioxidant activity of enzymatic extracts from brown seaweeds. Algae 2003;18:71-81.

15. Pyrzynska K, Pe A. Application of free radical diphenylpicrylhydrazyl (DPPH) to estimate the antioxidant capacity of food samples. Anal Methods 2013;5:4288-95.

16. Pothitirat W, Chomnawang MT, Supabphol R, Gritsanapan W. Comparison of bioactive compounds content, free radical scavenging and anti-acne inducing bacteria activities of extracts from the mangosteen fruit rind at two stages of maturity. Fitoterapia 2009;80:442-7.

17. Echeverría J, Opazo J, Mendoza L, Urzúa A, Wilkens M. Structureactivity and lipophilicity relationships of selected antibacterial natural flavones and flavanones of Chilean flora. Molecules 2017;22: E608.

18. Kabara JJ, Conley AJ, Truant JP. Relationship of chemical structure and antimicrobial activity of alkyl amides and amines. Antimicrob Agents Chemother 1972;2:492-8.

19. Ambarwati NS, Malik A, Elya B, Hanafi M. Profile of antibacterial activity of fractions from methanol extracts of Garcinia latissima miq. fruit rind. Asian J Pharma Clin Res 2017;10:66-8.

20. Ambarwati NS, Malik A, Deborah EA, Arpati SM, Hanif M, Elya B, et al. The antibacterial activity of fractions of ethyl acetate Garcinia latissima miq. Stem bark extracts against Bacillus subtilis and Pseudomonas aeruginosa. Asian J Pharma Clin Res 2017;10:69-72.

21. Ambarwati NS, Amarila M, Listari AT, Nirwana N, Elya B, Hanafi M. Antibacterial activity of fractions of ethyl acetate extract of Garcinia lattissima miq. Fruits. Asian J Pharma Clin Res 2017;10:81-4.

22. Horvath G, Kocsis B, Botz L, Nemeth J, Szabo L. Antibacterial activity of thymus phenols by direct bioautography. Proc Hung Plant phys 2002;46:145-6.

23. Nieva Moreno MI, Isla MI, Cudmani NG, Vattuone MA, Sampietro AR. Screening of antibacterial activity of Amaicha del Valle (Tucumán, Argentina) propolis. J Ethnopharmacol 1999;68:97-102.

24. Nostro A, Germanò MP, D'angelo V, Marino A, Cannatelli MA. Extraction methods and bioautography for evaluation of medicinal plant antimicrobial activity. Lett Appl Microbiol 2000;30:379-84.

25. Rahalison L, Hamburger M, Hostettmann K. A bioautographic agar overlay method for the detection of antifungal compounds from higher plants. Phytochem Anal 1991;2:199-203. 